\title{
Seroprevalence of Toxoplasmosis Among Pregnant Women Attending Antenatal Care in Asmara, Eritrea: Preliminary Report
}

\author{
Asmerom Seyoum Tecle ${ }^{1}$, Albadawi Abdelbagi Talha ${ }^{2}{ }^{\circledR}$, Khalid Abdelsamea Mohamedahmed $^{3 *}{ }^{(\mathbb{C}}$, Adam \\ Dawoud Abakar $^{4}$ \\ ${ }^{1}$ Department of Parasitology, National Health Laboratory, Asmara, Eritrea \\ ${ }^{2}$ Department of Clinical Laboratory Sciences, Jouf University of Gezira, Saudi Arabia \\ ${ }^{3}$ Department of Hematology and Immunology, Faculty of Medical Laboratory Science, University of Gezira, Wad Medani, \\ Sudan \\ ${ }^{4}$ Department of Medical Parasitology, Faculty of Medical Laboratory Science, University of Gezira, Wad Medani, Sudan
}

\begin{abstract}
Introduction: The majority of human infections with Toxoplasma gondii produce no symptoms, but in congenitally infected children can cause devastating effects including blindness, brain damage, or miscarriage. Transmission to the fetus occurs predominantly in women who acquire their primary infection during gestation. The study aimed to assess the seroprevalence of toxoplasmosis among pregnant women attending antenatal care (ANC) in different areas of Asmara, Eritrea, and to identify possible risk factors associated with toxoplasmosis among pregnant women attending the ANC centers.

Methods: In this cross-sectional laboratory-based study, the data were collected from 210 pregnant women in four health facilities. Voluntary sampling technique and a structured questionnaire were used to collect the associated data and socio-demographic information. Cobas e411 Analyzer was used to test the blood serum for immunoglobulin G (IgG) and Immunoglobulin M (IgM) antibodies. Epi-Info version 7.0 was used for data entry and SPSS version 20.0 was used for data analysis.

Results: Of the 210 samples, 112 (53.6\%) samples were seropositive and 97 (46.4\%) samples were seronegative for $T$. gondii specific $\lg$ antibody. Furthermore, $2.9 \%$ (6) of the samples were seropositive and $97.1 \%$ (203) of the samples were seronegative for T. gondii-specific IgM antibodies.

Conclusion: The seroprevalence was considerably high, 53.6\% for IgG antibody and $2.9 \%$ for IgM antibody, which require attention in order to implement preventive control measures, screening tests, and health education.

Keywords: Seroprevalence, Toxoplasmosis, Risk factors, Pregnant women, Eritrea
\end{abstract}

Received: November 9, 2020 , Accepted: December 11, 2020 ePublished: December 30, 2020

\section{Introduction}

Toxoplasma gondii is an obligate intra-cellular protozoan parasite that can infect most vertebrate animals and causes a disease called Toxoplasmosis (1). It was originally identified in a North African rodent called the gundi, from which it derives its specific name $(2,3)$. Humans can become infected by ingestion of oocysts released from cat feces, consumption of undercooked and raw meat, or drinking of unpasteurized milk containing $T$. gondii tissue cysts $(1,4)$. Transplacental congenital transmission of tachyzoites, blood transfusion, and organ transplantation were very rarely reported $(5,6)$. All stages can be infectious to humans (2). In severely infected women, Toxoplasmosis can be reactivated due to their immuno-compromised state (7). Recently, in immuno-competent individuals, more virulent strains that cause severe symptoms have been reported (8).

The diagnosis of infection is based on indirect serological tests, direct detection of the parasite, or polymerase chain reaction (PCR). Serologic tests indicating recent or past infection are most effective in immune-competent adults. ECLIA, ELISA, IFA, LA tests, and complement fixation are used to detect immunoglobulin $\mathrm{G}$ (IgG) and Immunoglobulin M (IgM) antibodies (9). The presence of a significant IgM titer in the absence of IgG titers indicates early stages of primary infection. The absence of IgM titer is assessed by ruling out recent infection. However, the presence of IgM antibody should be confirmed in a reference laboratory $(3,10)$. Currently, the diagnosis of an active toxoplasmosis of the fetus in utero is made by means of PCR of amniotic fluid (11).

Children above 5 years of age with severe acute 
infection or active chorioretinitis should be treated with pyrimethamine. Treatments of pregnant women are controversial but treatment with spiramycin is still advocated (12). A recent study confirmed that treating this infection during pregnancy prevents fetal toxoplasmosis (11).

It is noted that no study on the seroprevalence of toxoplasmosis either in general or specific target groups has been done in Eritrea. Nothing is known on what are the associated risk factors for the spread of the disease as well as its causes. Therefore, the purpose of this study was to assess the seroprevalence of toxoplasmosis and its associated risk factors among Eritrean pregnant women attending antenatal care (ANC) centers in Asmara.

\section{Materials and Methods \\ Study Area}

The study was performed in Asmara, Eritrea, at all the health facilities that provide maternal health services, including delivery, one hospital, and other three health facilities.

Eritrea is located in the horn of Africa bordered by the Sudan, Djibouti, Ethiopia, and the Red Sea with $1212 \mathrm{~km}$ seashore. It covers an area of $124000 \mathrm{~km}^{2}$ and is divided into three topographic areas (the Western Lowlands, the Central Highlands, and the Coastal Plains). Administratively, it is divided into 6 regions or zones, namely Northern Red Sea Zone, Southern Red Sea Zone, Anseba, Gash-Barka, Maekel and Southern Zone (Central Zone). The total population is about 6.1 million (13). Asmara is the targeted area of the study. It is the capital city of Eritrea and located in the central region (Zoba Maekel).

\section{Study Design, Study Population, and Sample Size}

In this cross-sectional laboratory-based study, all pregnant women (16-45 years) living in the catchment areas of Asmara administration were enrolled $(14,15)$.

The data were collected between July and August 2016 from 210 pregnant women (in 4 health facilities) attending their ANC follow-up. Voluntary sampling technique was used after obtaining their consent to participate in the research study.

\section{Data Collection Tools and Techniques}

A structured questionnaire was used to collect the pregnant women's socio-demographic information and the associated risk factors. Pregnant women were interviewed by the enumerators who were health professionals and worked in the facilities where the data collection was conducted.

\section{Collection of Sample and Laboratory Investigation}

In this study, $3 \mathrm{~mL}$ of venous blood was collected from study participants using standard procedures in Lithium heparin container and stored in freezing condition $\left(-20^{\circ} \mathrm{C}\right)$ before analysis. Then, serum was prepared by centrifugation at $2500 \mathrm{rpm}$ for 3 minutes.

The electrochemiluminescence immunoassay (ECLIA) was used for in-vitro quantitative measurement of IgG and IgM antibodies to T. gondii in serum of human on Cobas e411 immunoassay analyzer and Elecsys.

\section{Quality Control (QC)}

PreciControl was used for quality control. Controls for the various concentration ranges were run every day prior to and following each calibration. Based on the measurements of cal-1 and cal-2, the cut-off was calculated.

Interpretation: IgG: $>1$ (non-reactive), $\geq 1.0->30$ (Intermediate), $\geq 30$ (Reactive).

IgM: > 0.8 (non-reactive), $\geq 0.8->1.0$ (Intermediate), $\geq 1$ (Reactive).

\section{Data Entry and Data Analysis}

Data was collected using questionnaire then followed by data entry into computers using Epi-Info version 7.0, a free software package developed by CDC. To describe the data in terms of frequency and proportion, SPSS version 20.0 was used (16). To describe the age of participants, which is a continuous variable, mean and standard deviation were used (17). In this study, the chi-squared test was applied to screen for an association between seropositivity of IgG and IgM antibodies and several risk factors included in the study (18).

\section{Ethical Issues, Informed Consent, and Confidentiality}

This study was approved by the Ethics Committee of the University of Gezira. The Health Research Proposal Review and Ethical Committees, $\mathrm{MOH}$ Eritrea accepted and gave a permission to conduct the research on the specified sites. Ethical Permission was obtained from the Ministry of Health, Zoba Makel.

Participants were briefed about the objectives of this study and requested their willingness to participate in the study. The interview was carried out face-to-face to obtain information and the participants were kindly asked for their consent for enthusiastic participation.

\section{Results}

Socio-demographic Characteristics of Study Population Overall, 210 samples of pregnant women were collected from Edagahmus mini Hospital, Akria Health Center, Vilajo/BMCH Community Hospital, and Godief Health Center, constituting 80 (38\%), 50 (24\%), 41 (20\%) and 39 (19\%), respectively. Based on the results, $60 \%$ of the pregnant women were in the age group of 25 - 34 years, $27 \%$ were in age groups of $15-24$ years, and $13 \%$ were in the age group of 35-44 years. The mean and median age was 27 and 26 years, respectively with variation of 5 years by SD. 
Only $10 \%$ of the women were reported to be unmarried, divorced, widowed, or separated while the remaining $90 \%$ were married. Moreover, $98 \%$ of the participants were from Tigrigna ethnic group. Additionally, $70 \%$ of the pregnant women had secondary education, $16 \%$ had elementary education, and $14 \%$ had post-secondary education. In addition, $74 \%$ were housewives, $14 \%$ were daily workers, and $12 \%$ had other types of jobs. The majority (42\%) of the pregnant women were in their second trimester, 37\% were in their third trimester, and $21 \%$ were in their first trimester (Table 1).

\section{Detection of IgG and IgM Antibodies among Study}

Table 1. The Socio-demographic Information of Study Population

\begin{tabular}{|c|c|c|c|}
\hline Characteristics & & Number & Percent \\
\hline \multirow{4}{*}{ Health facility } & $\begin{array}{l}\text { Edagahamus mini } \\
\text { Hospital }\end{array}$ & 80 & 38 \\
\hline & Akria Health Center & 50 & 24 \\
\hline & $\begin{array}{l}\text { BMCH Community } \\
\text { Hospital }\end{array}$ & 41 & 20 \\
\hline & Godaif Health Center & 39 & 19 \\
\hline \multirow{3}{*}{ Age group } & $15-24$ years & 57 & 27 \\
\hline & $25-34$ years & 125 & 60 \\
\hline & $35-44$ years & 28 & 13 \\
\hline \multirow{2}{*}{ Marital status } & Married & 189 & 90 \\
\hline & Not married & 21 & 10 \\
\hline \multirow{3}{*}{ Education } & Primary & 33 & 16 \\
\hline & Secondary & 147 & 70 \\
\hline & University & 30 & 14 \\
\hline \multirow{3}{*}{ Pregnancy stage } & 1 st trimester & 77 & 36.7 \\
\hline & 2nd trimester & 88 & 41.9 \\
\hline & 3rd trimester & 45 & 21.4 \\
\hline \multirow{3}{*}{ Occupation } & Housewife & 155 & 74 \\
\hline & Daily worker & 29 & 14 \\
\hline & Others & 26 & 12 \\
\hline \multirow{4}{*}{ Ethnic groups } & Tigrigna & 205 & 98 \\
\hline & Tigre & 2 & 1 \\
\hline & Saho & 1 & 0.5 \\
\hline & Hidarb & 1 & 0.5 \\
\hline
\end{tabular}

\section{Population}

Of the total 209 pregnant women included in the study, 112 (53.6\%) were seropositive and 97 cases (46.4\%) were seronegative for $T$. gondii specific IgG antibody. Similarly, 6 samples (2.9\%) were seropositive and 203 samples (97.1\%) were seronegative (of which 2 samples were on the borderline) for T. gondii specific IgM antibody. Out of the total 112 IgG seropositive samples, 3 were also seropositive for $\operatorname{IgM}$, and out of the $97 \mathrm{IgG}$ seronegative samples, 3 were seropositive for IgM (Table 2).

\section{Distribution of IgG and IgM Seropositive Cases Among the Socio-demographic Characteristics and Risk Factors for Toxoplasma}

Tables 3 and 4 indicate the prevalence of seropositivity for $T$. gondii in socio-demographic categories (place, age, educational level, marital status, occupation, and stage of pregnancy) using IgG and IgM antibodies. Chisquare test was used to assess the association between $T$. gondii seropositivity and the factors, but no significant association was observed.

\section{Distribution of IgG and IgM Seropositive Cases Among Risk Factors for Toxoplasma Gondii}

Based on a different research study, possible risk factors were identified and included in this research study. These factors include source of water, use of raw meat, contact with soil, availability of domestic animals in general, and presence of a cat in particular. In addition to them (3), possible health factors such as history of abortion, HIV status, and presence of mentally abnormal child were also included (Tables 5 and 6). Chi-square test showed some significant associations between T. gondii seropositivity and contact with soil, but no significant association was observed for other factors.

\section{Discussion}

Several research studies have noted that toxoplasmosis is a food-borne infectious disease which is the third leading cause of death after salmonellosis and listeriosis (19). Though it is highly neglected, congenital T. gondii infection particularly is a common problem in communities with a high prevalence of infection. Epidemiological studies

Table 2. Association between $\lg G$ and $\lg M$ Antibodies

\begin{tabular}{lccccc}
\hline & & \multicolumn{2}{c}{ IgM Status } & \multirow{2}{*}{ Total } \\
\cline { 3 - 4 } & & Negative (-ve) & Positive (+ve) & \\
\hline \multirow{3}{*}{ IgG Status } & Negative (-ve) & Cases & 94 & 3 & 97 \\
& & Percent & 45.0 & 1.45 & 46.4 \\
& Positive (+ve) & Cases & 109 & 3 & 112 \\
Total & Percent & 52.1 & 6 & 53.6 \\
& & Cases & 203 & 2.9 & 209 \\
\hline
\end{tabular}


Table 3. Distribution of IgG Antibody Among the Different Characteristics

\begin{tabular}{|c|c|c|c|c|c|c|}
\hline \multirow{2}{*}{\multicolumn{2}{|c|}{ Socio-demographic Characteristics }} & \multicolumn{4}{|c|}{ IgG Status } & \multirow{3}{*}{ Total $(\mathbf{N})$} \\
\hline & & \multicolumn{2}{|c|}{ Negative (-ve) } & \multicolumn{2}{|c|}{ Positive (+ve) } & \\
\hline & & No. & $\%$ & No. & $\%$ & \\
\hline \multirow{4}{*}{ Health Facility } & Edagahamus & 45 & 56.2 & 35 & 43.8 & 80 \\
\hline & Akria & 20 & 40.0 & 30 & 60.0 & 50 \\
\hline & $\mathrm{BMCH}$ & 16 & 40.0 & 24 & 60.0 & 41 \\
\hline & Godaif & 16 & 41.0 & 23 & 59.0 & 39 \\
\hline \multirow{3}{*}{ Age group } & $15-24$ & 32 & 56.1 & 25 & 43.9 & 57 \\
\hline & $25-34$ & 56 & 44.8 & 69 & 55.2 & 125 \\
\hline & $35-44$ & 9 & 33.3 & 18 & 66.7 & 28 \\
\hline \multirow{2}{*}{ Marital status } & Married & 84 & 44.4 & 105 & 55.6 & 189 \\
\hline & Not married & 13 & 65.0 & 7 & 35.0 & 21 \\
\hline \multirow{3}{*}{ Education } & Primary & 16 & 50.0 & 16 & 50.0 & 33 \\
\hline & Secondary & 68 & 46.3 & 79 & 53.7 & 147 \\
\hline & Above & 13 & 43.3 & 17 & 56.7 & 30 \\
\hline \multirow{3}{*}{ Occupation } & Housewife & 68 & 43.9 & 87 & 56.1 & 155 \\
\hline & Daily worker & 17 & 58.6 & 12 & 41.4 & 29 \\
\hline & Other & 12 & 48.0 & 13 & 52.0 & 26 \\
\hline \multirow{3}{*}{ Pregnancy stage } & 1st trimester & 21 & 46.7 & 24 & 53.3 & 45 \\
\hline & 2nd trimester & 43 & 48.9 & 45 & 51.1 & 88 \\
\hline & 3rd trimester & 33 & 43.4 & 43 & 56.6 & 77 \\
\hline Total & & 97 & 46.4 & 112 & 53.6 & 210 \\
\hline
\end{tabular}

Table 4. Distribution of IgM Antibody Among the Different Characteristics

\begin{tabular}{|c|c|c|c|c|c|c|}
\hline \multirow{3}{*}{\multicolumn{2}{|c|}{ Socio-demographic Characteristics }} & \multicolumn{4}{|c|}{ IgM Status } & \multirow{3}{*}{ Total (N) } \\
\hline & & \multicolumn{2}{|c|}{ Negative (-ve) } & \multicolumn{2}{|c|}{ Positive (+ve) } & \\
\hline & & No. & $\%$ & No. & $\%$ & \\
\hline \multirow{4}{*}{ Health Facility } & Edagahamus & 77 & 96.2 & 3 & 3.8 & 80 \\
\hline & Akria & 48 & 96.0 & 2 & 4.0 & 50 \\
\hline & $\mathrm{BMCH}$ & 41 & 100.0 & 0 & 0.0 & 41 \\
\hline & Godaif & 38 & 97.4 & 1 & 2.6 & 39 \\
\hline \multirow{3}{*}{ Age group } & $15-24$ & 57 & 100.0 & 0 & 0.0 & 57 \\
\hline & $25-34$ & 119 & 95.2 & 6 & 4.8 & 125 \\
\hline & $35-44$ & 28 & 100.0 & 0 & 0.0 & 28 \\
\hline \multirow{2}{*}{ Marital status } & Married & 185 & 97.9 & 4 & 2.1 & 189 \\
\hline & Not married & 19 & 90.5 & 2 & 9.5 & 21 \\
\hline \multirow{3}{*}{ Education } & Primary & 31 & 93.9 & 2 & 6.1 & 33 \\
\hline & Secondary & 143 & 97.3 & 4 & 2.7 & 147 \\
\hline & Above & 30 & 100.0 & 0 & 0.0 & 30 \\
\hline \multirow{3}{*}{ Occupation } & Housewife & 151 & 97.4 & 4 & 2.6 & 155 \\
\hline & Daily worker & 29 & 100.0 & 0 & 0.0 & 29 \\
\hline & Other & 24 & 92.3 & 2 & 7.7 & 26 \\
\hline \multirow{3}{*}{ Pregnancy stage } & 1st trimester & 43 & 95.6 & 2 & 4.4 & 45 \\
\hline & 2nd trimester & 86 & 97.7 & 2 & 2.3 & 88 \\
\hline & 3rd trimester & 75 & 97.4 & 2 & 2.6 & 77 \\
\hline \multicolumn{2}{|l|}{ Total } & 204 & 97.1 & 6 & 2.9 & 210 \\
\hline
\end{tabular}


Table 5. Distribution of IgG Antibody Among the Different Risk Factors of Toxoplasma Gondii

\begin{tabular}{|c|c|c|c|c|c|c|c|}
\hline \multirow{3}{*}{ Risk factors } & & \multicolumn{4}{|c|}{ IgG Status } & \multirow{2}{*}{\multicolumn{2}{|c|}{ Total }} \\
\hline & & \multicolumn{2}{|c|}{ Negative (-ve) } & \multicolumn{2}{|c|}{ Positive (+ve) } & & \\
\hline & & $\mathrm{N}$ & $\%$ & $\mathbf{N}$ & $\%$ & $\mathbf{N}$ & $\%$ \\
\hline \multirow{3}{*}{ Source of water } & Pipe water & 70 & 46.7 & 80 & 53.3 & 150 & 71.4 \\
\hline & Well & 5 & 62.5 & 3 & 37.5 & 9 & 4.3 \\
\hline & Other & 22 & 43.1 & 29 & 56.9 & 51 & 24.3 \\
\hline \multirow{2}{*}{ Use of raw meat } & No & 92 & 46.9 & 104 & 53.1 & 197 & 93.8 \\
\hline & Yes & 5 & 38.5 & 8 & 61.5 & 13 & 6.2 \\
\hline \multirow{2}{*}{ Availability of cat } & No & 71 & 45.5 & 85 & 54.5 & 157 & 74.8 \\
\hline & Yes & 26 & 49.1 & 27 & 50.9 & 53 & 25.2 \\
\hline \multirow{2}{*}{ Availability of other domestic animals } & No & 73 & 48.7 & 77 & 51.3 & 150 & 71.4 \\
\hline & Yes & 24 & 40.7 & 35 & 59.3 & 60 & 28.6 \\
\hline \multirow{2}{*}{ Contact with soil } & No & 94 & 48.2 & 101 & 51.8 & 196 & 93.3 \\
\hline & Yes & 3 & 21.4 & 11 & 78.6 & 14 & 6.7 \\
\hline \multirow{2}{*}{ HIV status } & No & 97 & 100. & 111 & 99.1 & 209 & 99.5 \\
\hline & Yes & 0 & 0.0 & 1 & 0.9 & 1 & 0.5 \\
\hline \multirow{2}{*}{ Abortion status } & No & 87 & 49.2 & 90 & 50.8 & 178 & 84.8 \\
\hline & Yes & 10 & 31.2 & 22 & 68.8 & 32 & 15.2 \\
\hline \multirow{2}{*}{ Child with a mental problem } & No & 91 & 46.7 & 104 & 53.3 & 195 & 92.9 \\
\hline & Yes & 6 & 42.9 & 8 & 57.1 & 15 & 7.1 \\
\hline Total & & 97 & 46.4 & 112 & 53.6 & 210 & 100.0 \\
\hline
\end{tabular}

Table 6. Distribution of IgM Antibody among the Different Risk Factors of Toxoplasma Gondii

\begin{tabular}{|c|c|c|c|c|c|c|c|}
\hline \multirow{3}{*}{ Risk factors } & & \multicolumn{4}{|c|}{ IgM Status } & \multirow{2}{*}{\multicolumn{2}{|c|}{ Total }} \\
\hline & & \multicolumn{2}{|c|}{ Negative (-ve) } & \multicolumn{2}{|c|}{ Positive (+ve) } & & \\
\hline & & No. & $\%$ & No. & $\%$ & No. & $\%$ \\
\hline \multirow{3}{*}{ Source of water } & Pipe water & 148 & 98.7 & 2 & 1.3 & 150 & 71.4 \\
\hline & Well & 9 & 100.0 & 0 & 0.0 & 9 & 4.3 \\
\hline & Other & 47 & 92.2 & 4 & 7.8 & 51 & 24.3 \\
\hline \multirow{2}{*}{ Use of raw meat } & No & 192 & 97.5 & 5 & 2.5 & 197 & 93.8 \\
\hline & Yes & 12 & 92.3 & 1 & 7.7 & 13 & 6.2 \\
\hline \multirow{2}{*}{ Availability of cat } & No & 152 & 96.8 & 5 & 3.2 & 157 & 74.8 \\
\hline & Yes & 52 & 98.1 & 1 & 1.9 & 53 & 25.2 \\
\hline \multirow{2}{*}{ Availability of other domestic animals } & No & 147 & 98.0 & 3 & 2.0 & 150 & 71.4 \\
\hline & Yes & 57 & 95.0 & 3 & 5.0 & 60 & 28.6 \\
\hline \multirow{2}{*}{ Contact with soil } & No & 190 & 96.9 & 6 & 3.1 & 196 & 93.3 \\
\hline & Yes & 14 & 100.0 & 0 & 0.0 & 14 & 6.7 \\
\hline \multirow{2}{*}{ HIV status } & No & 203 & 99.5 & 6 & 100.0 & 209 & 99.5 \\
\hline & Yes & 1 & 0.5 & 0 & 0.0 & 1 & 0.5 \\
\hline \multirow{2}{*}{ Abortion status } & No & 173 & 97.2 & 5 & 2.8 & 178 & 84.8 \\
\hline & Yes & 31 & 96.9 & 1 & 3.1 & 32 & 15.2 \\
\hline \multirow{2}{*}{ Child with a mental problem } & No & 190 & 97.4 & 5 & 2.6 & 195 & 92.9 \\
\hline & Yes & 14 & 93.3 & 1 & 6.7 & 15 & 7.1 \\
\hline Total & & 204 & 97.1 & 6 & 2.9 & 210 & 100.0 \\
\hline
\end{tabular}

reporting the prevalence of toxoplasmosis in pregnant women across the world suggest considerable variation between areas, ranging between $9 \%$ and $67 \%$ in Europe and reaching as high as $92.5 \%$ in African countries (6). Therefore, conducting a study on the seroepidemiology of $T$. gondii infection among women of childbearing age 
may give appropriate information which could help to design preventive measures (3).

A recent study showed a seroprevalence of $53.6 \%$ among 210 pregnant women in Asmara. Even though these pregnant women were not at risk of getting $T$. gondii infection, because they have already developed IgG antibodies, the remaining $46.4 \%$ were at risk of getting the infection. Additionally, the seroprevalence of toxoplasmosis was noted to be $2.9 \%$, which is lower compared with many countries. In Saudi Arabia, the prevalence of T. gondii IgG and IgM antibodies during pregnancy was $32.5 \%$ and $6.4 \%$, respectively (14).

As it was indicated, the study was done on pregnant women in Asmara. Asmara is the capital city of Eritrea where the majority of its population have better access to different social services such as access to clean water for drinking, sanitation and hygiene, health, and education (15). Had it been conducted in other rural parts of the countries where access to social services is relatively low, the seroprevalence would have been increased.

In this study, the seroprevalence of IgG antibody among the pregnant women was $53.6 \%$, which is higher compared to others studies done in other countries. For instance, the prevalence was $30.9 \%$ in Tanzania (20), 15.2\% in Eastern China (6), 27\% in Sudan (9), and $43.8 \%$ in France (21) and lower compared to other countries such as Cameron with $77.1 \%$ in 1992 , Ethiopia with $80.0 \%$ in 1998, Argentina with $72 \%$ in 2001, Indonesia with 58\% in 2000 (22) and Kinshasa, D.R of Congo with 80.3\% (23).

Though, the result revealed that there was no association between seropositivity of $T$. gondii and different age groups, the seropositivity rate was obviously higher in the age group of 35-44 years compared to other two groups. Despite small variation in age groups, the result is in line with studies from other countries $(20,24)$. However, a comparative study done on pregnant women in Malaysian and Myanmar has identified that T. gondii seropositivity was found to have an association with the age group of 30 years and above (18). The study conducted among the pregnant women in Malaysia has also identified that mothers' education, gestational age, gravida, awareness of disease, obstetric history, having contact with soil or cats, consumption of undercooked meat, use of untreated water, and consumption of unpasteurized milk have a relationship with toxoplasmosis. Though this is the first study ever done on toxoplasmosis in the country, the result showed that the seroprevalence of toxoplasmosis was considerably high (53.6\%) using IgG antibody. When IgM antibody was considered, the disease prevalence was noted to be $2.9 \%$. It has been noted that the areas of the study were located in Asmara where the exposure to risk factors is relatively minimal. Therefore, even considering this, the result was higher which requires attention. The results also showed that except for contact with soil, none of the risk factors included in the study had any significant association with the disease pattern.

\section{Conclusion}

The absence of a statistically significant association between the prevalence of toxoplasmosis and many of the studied risk factors does not necessarily mean that these factors have no relationship with the transmission of T. gondii infection. This could be due to the test method which demands a higher number of disease cases. Probably a lager sample size would have revealed significant relationships.

\section{Conflict of Interests}

In this study, we declare that we have no conflict of interests.

\section{Ethical Issues}

In this study, ethical considerations have been fully observed.

\section{Acknowledgment}

We would like to acknowledge the staff of Antenatal Care (ANC) in Asmara City, Eritrea and all the patients who participated in the study.

\section{Authors' Contribution}

AST and AAT designed the study and did data collection. AST, AAT and KAM did writing of the original draft. KAM and ADA did editing and reviewing of the original article.

\section{Funding}

No financial support was received for the original article from any funding agencies.

\section{References}

1. Gilot-Fromont E, Lélu M, Dardé ML, et al. The Life Cycle of Toxoplasma gondii in the Natural Environment. IntechOpen; 2012. doi:10.5772/48233

2. John DT, Petri WA. Markell and Voge's Medical Parasitology. 9th ed. St. Louis: Elsevier Inc; 2006.

3. Cheesbrough M. District Laboratory Practice in Tropical Countries, Part 1. 2nd ed. ambridge University Press; 2009:300-302.

4. Food Standards Agency. Annual Report and Consolidated Accounts 2012/13. Food Standards Agency; 2013.

5. Dubey JP, Jones JL. Toxoplasma gondii infection in humans and animals in the United States. Int J Parasitol. 2008;38(11):1257-1278. doi:10.1016/j.ijpara.2008.03.007

6. Cong W, Dong XY, Meng QF, et al. Toxoplasma gondii infection in pregnant women: a seroprevalence and case-control study in Eastern China. Biomed Res Int. 2015;2015:170278. doi:10.1155/2015/170278

7. Montoya JG, Remington JS. Management of Toxoplasma gondii infection during pregnancy. Clin Infect Dis. 2008;47(4):554-566. doi:10.1086/590149

8. Tekkesin N. Diagnosis of toxoplasmosis in pregnancy: a review. HOAJ Biol. 2012;1(1):1-8. doi:10.7243/2050-0874$1-9$

9. Mustafa M, Fathy F, Mirghani A, et al. Prevalence and risk factors profile of seropositive Toxoplasmosis gondii infection among apparently immunocompetent Sudanese 
women. BMC Res Notes. 2019;12(1):279. doi:10.1186/ s13104-019-4314-0

10. Agmas B, Tesfaye R, Koye DN. Seroprevalence of Toxoplasma gondii infection and associated risk factors among pregnant women in Debre Tabor, Northwest Ethiopia. BMC Res Notes. 2015;8:107. doi:10.1186/s13104015-1083-2

11. Paquet C, Yudin MH. Toxoplasmosis in pregnancy: prevention, screening, and treatment. J Obstet Gynaecol Can. 2013;35(1):78-81. doi:10.1016/s1701-2163(15)310537

12. Satoskar AR, Simon GL, Hotez PJ, Tsuji M. Medical Parasitology. Austin, Texas: Landes Bioscience; 2009:129135.

13. WHO, UNICEF, UNFPA, World Bank Group and United Nations Population Division Maternal Mortality Estimation Inter-Agency Group (2015) Maternal mortality in 1990-2015: Eritrea. Available at http://www.who.int/ gho/maternal_health/countries/eri.pdf?ua=1. Accessed May 16, 2017.

14. Alghamdi J, Elamin MH, Alhabib S. Prevalence and genotyping of Toxoplasma gondii among Saudi pregnant women in Saudi Arabia. Saudi Pharm J. 2016;24(6):645651. doi:10.1016/j.jsps.2015.05.001

15. National Statistics and Evaluation Office (NSEO) (Eritrea) and ORC Macro (2003) Eritrea Demographic and Health Survey 2002, p.197. Calverton, Maryland, USA: National Statistics and Evaluation Office and ORC Macro. Available at http://dhsprogram.com/what-we-do/survey/surveydisplay-170.cfm. Accessed May 22, 2017.

16. Bruce N, Pope D, Stanistreet D. Quantitative Methods for Health Research: A Practical Interactive Guide to Epidemiology and Statistics. 2nd ed. Chichester, UK: John
Wiley \& Sons Ltd; 2018.

17. Petrie A, Sabin C. Medical Statistics at a Glance. 4th ed. USA: Wiley-Blackwell; 2019.

18. Steward A. Basic Statistics and Epidemiology: A Practical Guide. 4th ed. United Kingdom: Radcliffe Medical Press Ltd; 2016.

19. Mehlhorn H. Human Parasites: Diagnosis, Treatment, Prevention. Switzerland: Springer International Publishing; 2016. doi:10.1007/978-3-319-32802-7

20. Mwambe B, Mshana SE, Kidenya BR, et al. Seroprevalence and factors associated with Toxoplasma gondii infection among pregnant women attending antenatal care in Mwanza, Tanzania. Parasit Vectors. 2013;6:222. doi:10.1186/1756-3305-6-222

21. Ghazaei C. Serological survey of antibodies to Toxoplasma gondii. Afr J Health Sci. 2006;13(1-2):131-134.

22. Murebwayire E, Njanaake K, Ngabonziza JC, Jaoko W, Njunwa KJ. Seroprevalence and risk factors of Toxoplasma gondii infection among pregnant women attending antenatal care in Kigali, Rwanda. Tanzan J Health Res. 2017;19(1):1-8. doi:10.4314/thrb.v19i1.2

23. Doudou Y, Renaud P, Coralie L, et al. Toxoplasmosis among pregnant women: high seroprevalence and risk factors in Kinshasa, Democratic Republic of Congo. Asian Pac J Trop Biomed. 2014;4(1):69-74. doi:10.1016/s22211691(14)60211-2

24. Kolbekova P, Kourbatova E, Novotna M, Kodym P, Flegr J. New and old risk-factors for Toxoplasma gondii infection: prospective cross-sectional study among military personnel in the Czech Republic. Clin Microbiol Infect. 2007;13(10):1012-1017. doi:10.1111/j.14690691.2007.01771.x 